\title{
SILVER-CONTAINING CARBON FIBERS, PREPARATION AND PROPERTIES
}

\author{
A. A. Lysenko, ${ }^{*}$ N. G. Medvedeva, ** \\ B. L. Gorberg, *** I. L. Kuzikova,** \\ O. V. Astashkina,* and N. F. Uvarova*
}

UDC 66.022.39

\begin{abstract}
Various methods for preparing fibrous materials [substrates in which polymer filaments of various nature are decorated with particles and/or layers of metallic silver $(\mathrm{Ag})]$ are compared and analyzed. Ion-plasma magnetron sputtering is shown to be the most promising method for modifying materials made of polypropylene and fluoroplastic fibers with Ag. Reductive adsorption is the most effective method for surface modification of carbon fibers with Ag. Photographs taken on a scanning electron microscope that characterize the morphology of Ag-containing fibers are presented. The bactericidal activity of Ag-containing fibers of various types is demonstrated. Hypotheses explaining the high antimicrobial activity of Ag-modified carbon fibers are proposed.
\end{abstract}

The key issue in practically all of thousands of publications dedicated to research on silver (Ag)-containing materials, including Ag-containing nanoparticles, is the bactericidal, bacteriostatic, fungicidal, or antiviral properties of such materials. At least one of the research problems in almost all such publications is elucidation of the mechanism of bactericidal action of Ag ions or particles [1-5]. Questions of the production (synthesis) of Ag-containing materials, including nanoparticles of various compositions and morphologies [3-6] and textiles and implants decorated with Ag [7-9], are discussed to a lesser extent in them.

Progress in the application of Ag in antimicrobial and even antiviral drugs and coatings is particularly interesting because they possess a complex of biocidal properties even against antibiotic-resistant pathogenic species. Also, Ag possesses wound-healing activity and is an immunomodulator that activates significantly human defensive responses [9].

Ag-containing textiles have been broadly applied in medical practice [10-13]. Currently, the development of absorptive and filtering textiles (cloth and non-woven) with antiviral activity, especially against coronaviruses, is a critical task.

Metal-containing absorbents capable of selectively extracting flu viruses from biological fluids, e.g., allantoic fluids, were developed at the start of the 1980s at the Department of Chemical Fiber Technology, Leningrad Institute of Textile and Light Industry (now the Department of Nanostructural, Fibrous, and Composite Materials, St. Petersburg State University of Industrial Technologies and Design) [14-16]. This research was conducted in collaboration with researchers from the Research Institute of Influenza, Russian Academy of Medical Sciences. Ion-exchange fibers acted as polymer supports in such absorbents; ultradisperse $\mathrm{Ag}$, copper $(\mathrm{Cu})$, and nickel (Ni) (nano- and microparticles), as active absorbent phases. Photographs of colonies of Leningrad influenza A virions were obtained and the dimensions of viruses and metal particles on the filament surface were estimated using electron microscopy (Fig. 1). The length of the virions was $2.5 \mu \mathrm{m}$; thickness, $0.2 \mu \mathrm{m}$; Ag particle size, 0.1-3.0 $\mu \mathrm{m}$.

Metal-containing absorbents were prepared according to the following method:

- a carboxyl-containing cation-exchanger was synthesized;

- $\mathrm{Ag}, \mathrm{Cu}$, or $\mathrm{Ni}$ cations were bound in the ion-exchange fiber structure from solutions with various metal concentrations;

*St. Petersburg State University of Industrial Technologies and Design; **St. Petersburg Scientific Research Center for Ecological Safety, Russian Academy of Sciences; ***Ivanovo State University of Chemistry and Technology; E-mail: thvikm@yandex.ru. Translated from Khimicheskie Volokna, No. 5, pp. 9-14, September- October, 2020. 


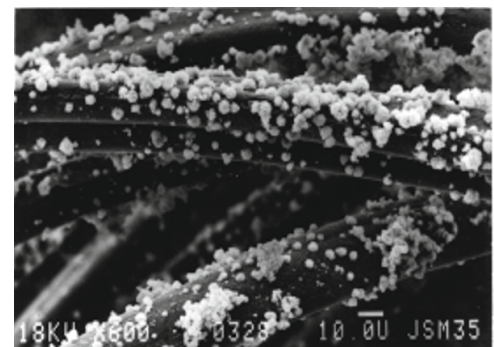

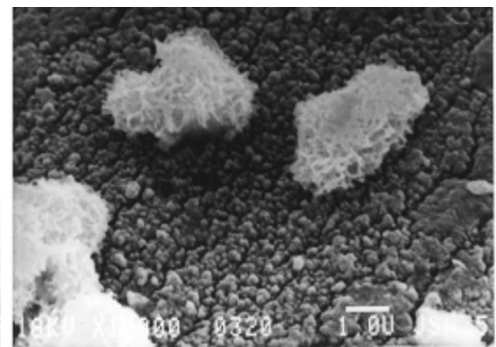

$b$

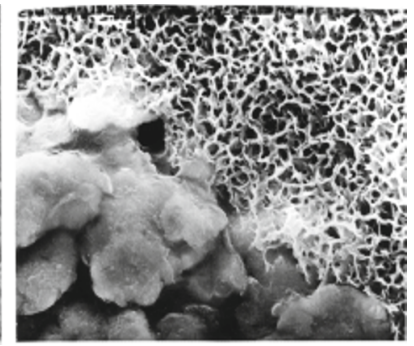

Fig. 1. Virus colonies on surface of Ag-containing ion-exchange fibers: globules of virus colonies on fiber surface (a); agglomerate of viruses and fiber surface coated with Ag particles (b); flu virions (elongated particles) forming agglomerates (c). Photographs taken on JSM scanning electron microscope (JEOL, Japan).

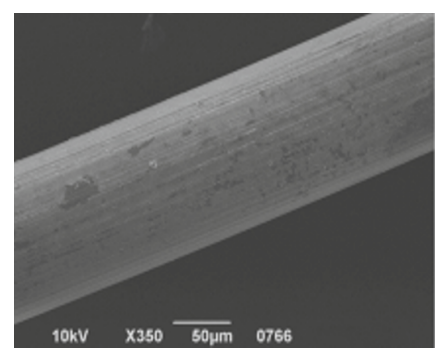

$a$

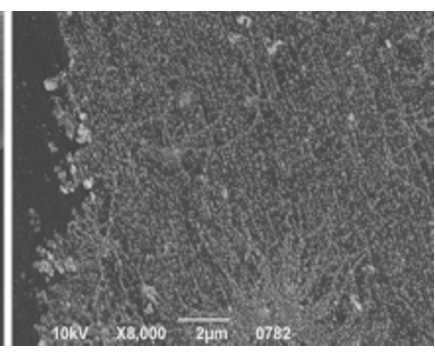

$b$

Fig. 2. Photographs of PP fibers taken on a JSM scanning electron microscope (JEOL, Japan) [10]: fibers coated with a layer of Ag (a) and Ag layer morphology (b).

- the metal ions were reduced to $\mathrm{Ag}^{0}, \mathrm{Cu}^{0}$, or $\mathrm{Ni}^{0}$ with heating in solutions of hydrazine hydrate.

The above method for preparing metal-containing fiber composites was especially effective if ion-exchangers (granulated or fibrous) were used as substrates because the metals being reduced could be bound directly in the ionexchanger bulk. In turn, this allowed them to be reduced on the outer surface of the substrate particles without being leached into the reductant solution, i.e., practically without losses.

An analogous method for preparing Ag-containing fibrous materials by chemical reduction of Ag ions was reported [10]. The preparation method could be represented as follows:

- $\mathrm{AgNO}_{3}$ solutions in DMSO were prepared;

- a fibrous polymer material made of polypropylene (PP) or polyvinylidenefluoride (PVDF) threads was impregnated with the $\mathrm{AgNO}_{3}$ solution in DMSO;

- the materials were dried after impregnation and impregnated and dried again;

- the dried fibrous material was treated with $\mathrm{NaOH}$ solution and then ammonia solution;

- the fibrous polymer substrate was treated with a reductant, i.e., an aqueous solution of glucose, directly in an ammonia solution of $\mathrm{Ag}$ so that metallic $\mathrm{Ag}$ precipitated on the fibers;

- the fibers were rinsed and dried.

In our opinion, the above scheme does have some drawbacks. It has one step in which reduction of $\mathrm{Ag}$ in an ammonia solution forms nanoparticulate and colloidal $\mathrm{Ag}^{0}$, basically a side product. Apparently, PVDF fibers are more effective for preparing Ag-containing materials because they can swell more than PP fibers in DMSO solutions containing Ag ions.

Treatment of PP fibers with a low-temperature plasma was proposed by us for stronger binding of Ag ions in their structure. This would form surface phenol and carboxylic acids groups that would actively absorb and bind Ag ions [10].

An almost continuous metal coating, which is clearly visible as a formation of Ag nanoparticles of sizes 40-100 $\mathrm{nm}$ (Fig. 2), formed upon reduction of Ag on PP and PVDF fibers. 


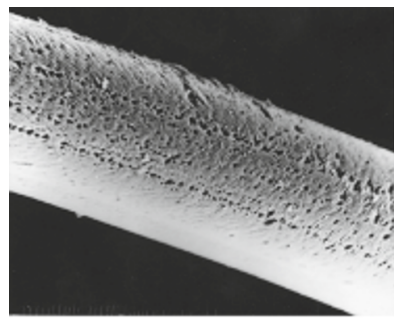

$a$

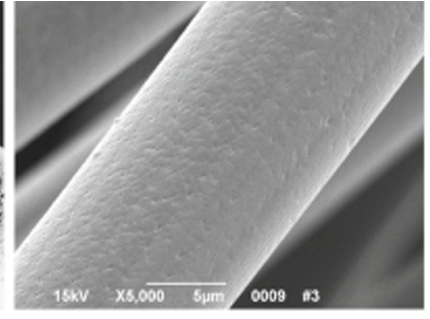

$b$

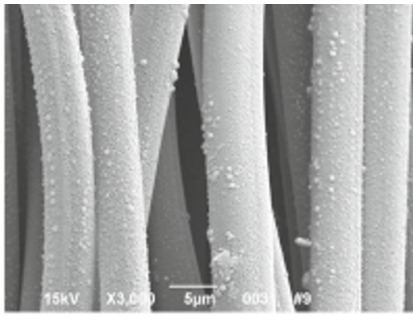

$c$

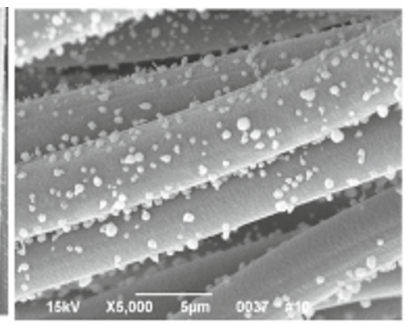

$d$

Fig. 3. Photographs of surface of carbon fibers taken on a JSM scanning electron microscope (JEOL, Japan): activated CF (ACF) (a), graphitized CF (b), ACF-AG (c), CF-Ag (d).

Table 1. Characteristics of GCF, ACF, GCF-Ag, and ACF-Ag Materials

\begin{tabular}{l|c|c|c|c|c|c}
\hline \multirow{2}{*}{ Mat erial } & \multirow{2}{*}{$\begin{array}{c}\text { Volu me of } \\
\text { toluene sorption } \\
\text { space, } \mathrm{cm}^{3} / \mathrm{g}\end{array}$} & \multicolumn{2}{|c|}{$\begin{array}{c}\text { Electrical resistance, } \\
\mathrm{m} \Omega \cdot \mathrm{m}\end{array}$} & \multicolumn{2}{c|}{$\begin{array}{c}\text { Ag layer } \\
\text { thickness, } \mathrm{nm}\end{array}$} & \multirow{2}{*}{$\begin{array}{c}\text { Spherulite and } \\
\text { toroid sizes, } \mathrm{nm}\end{array}$} \\
\cline { 3 - 6 } & 0.08 & cut fibers & cloth & AFM & JSM & \\
\hline GCF & 0.0 .15 & 0.020 & - & - & - \\
ACF & 0.41 & ODL $^{*}$ & ODL* & - & - & - \\
GCF-Ag & 0.05 & 0.13 & 0.015 & 60 & 120 & $96-248$ \\
ACF-Ag & 0.32 & 0.10 & 0.020 & 60 & 130 & $70-79$ \\
\hline
\end{tabular}

*ODL - above determination limit.

In our opinion, a method based on redox absorption of $\mathrm{Ag}$ by activated carbon fibers (ACF) is one of the simplest and most effective methods for producing Ag-containing fibrous materials [17].

The method for preparing woven, weaved, or non-woven materials from ACF is as follows:

- $\mathrm{ACF}$ are placed into an aqueous $\mathrm{AgNO}_{3}$ solution and stored in it for 10 to $30 \mathrm{~min}$;

- the excess of the solution is removed from the material on a vacuum filter; the material is rinsed with $\mathrm{H}_{2} \mathrm{O}$ until traces of $\mathrm{Ag}$ ions are absent;

- the material with the bound Ag particles is dried in the final step.

Spherical particles of metallic Ag of sizes from hundreds of nanometers to 2-3 $\mu \mathrm{m}$ formed on the filament surfaces upon modification of $\mathrm{ACF}$ by $\mathrm{AgNO}_{3}$ solutions of low concentrations. If the concentrations of the $\mathrm{AgNO}_{3}$ solutions were high, then part of the Ag was reduced as crystals or even a coating of crystals.

Not only activated but also graphitized carbon fibers (GCF) containing Ag were prepared by us using reductive adsorption [17]. Figure 3 shows surface morphologies of starting ACF and GCF and the Ag-containing filaments.

Important advantages of the reductive adsorption method were as follows. Expensive fittings and equipment were not needed. The content of reduced Ag in the substrate structure was easily controlled and provided. The degree of extraction of Ag ions from the solution reached $96-98 \%$ and could be driven to $100 \%$ (i.e., no Ag waste). The method could produce not only Ag-containing but also Au-containing materials.

However, the above method for preparing Ag-containing fibrous materials could not be used for all types of fibers, e.g., for fluoroplastics, polyolefins, polyamides, etc., despite its simplicity.

Therefore, it seemed interesting to examine ion-plasma magnetron sputtering (IPMS) of metals, in particular Ag. This method has been discussed in detail [11]. Photographs of metallized materials are accessible on the website http://ivtechnomash.ru.

In our opinion, the following are noteworthy advantages of the method: solvent-free, high precipitation rate of metals or their compounds, highly pure coatings, ability to create semi-continuous lines (i.e., practically industrial manufacturing of metal-containing textiles).

In addition, the IPMS (sputtering) method requires the use of expensive and rather complicated equipment. The Ag content on the surface of textile items is impossible or very difficult to control if this method is used (at least, we know of no research in this area). In many instances, magnetron sputtering cannot produce fibrous substrates in which metallic $\mathrm{Ag}$ would be bound in the material bulk and not on its surface so that the coating would be naturally layered. 

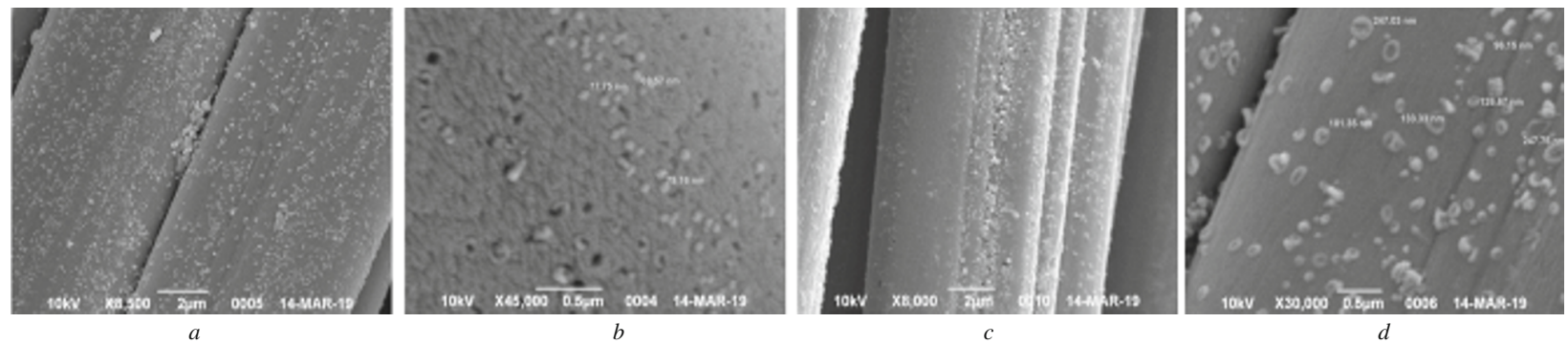

Fig. 4. Photographs of surface of fibers taken on a JSM scanning electron microscope (JEOL, Japan): surface morphology of ACF-Ag filaments (a); spherulites on surface of ACF-Ag filaments (b); surface morphology of GCF-Ag filaments (c); toroidal Ag particles on surface of GCF-Ag filaments (d).

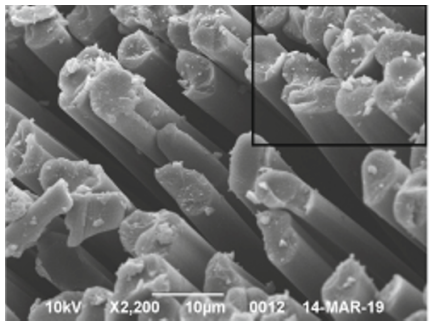

$a$

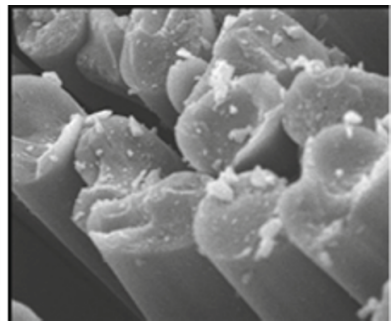

Fig. 5. Photographs of carbon filaments taken on a JSM scanning electron microscope (JEOL, Japan): GCF-Ag (a) and magnified fragment with separate coating (b).

Obviously, other methods for preparing Ag-containing textiles are possible besides those discussed above, e.g., electrochemical precipitation, vacuum deposition, or an exotic method such as explosion sputtering [18].

The goal of the present work was to study the properties of Ag-containing carbon-fiber materials produced by IPMS

The carbon-fiber substrates and supports for Ag precipitation were graphitized cloth and cloth made of activated fibers that were arbitrarily called GCF and ACF, respectively. The Ag-containing substrates in this article were called GCF-Ag and ACF-Ag. Ag was sputtered on a UMN 180 unit with an exposure time of $60 \mathrm{~s}$. The technical characteristics of the unit were reported before [11].

Table 1 lists the main characteristics of the carbon-fiber materials.

The electrical resistance of the fibrous materials was experimentally determined using a four-contact method (the Van Der Paauw method for cut fibers). The thickness of the sputtered Ag layer on the fibers was measured on an AFM scanning probe microscope by comparison with the thickness of an Ag layer sputtered on a Si substrate for the same exposure time. The thickness of the Ag layer, surface morphology, and Ag particle size were also estimated by analyzing photographs obtained using a JSM scanning microscope (JEOL). The results showed that the GCF were practically not absorbents because their absorption space had a volume $\leq 0.1 \mathrm{~cm}^{3} / \mathrm{g}$. The activated fibers both before and after sputtering could absorb large organic ions, e.g., methylene blue dye [19]. Starting GCF (in cloth) and GCF-Ag had high electrical conductivity (low specific resistance $\leq 0.03 \mathrm{~m} \Omega \cdot \mathrm{m}$ ). The electrical conductivity of ACF-Ag was significantly (by several orders of magnitude) greater than that of the starting ACF. The specific resistance of ACF-Ag (for cloth) was $0.02 \mathrm{~m} \Omega \cdot \mathrm{m}$. The thickness of the Ag layer precipitated on the fibers was $60 \mathrm{~nm}$ according to probe microscopy; $120-130$ $\mathrm{nm}$, according to scanning electron microscopy. Also, the particle size of Ag (spherulites and toroids) in the surface layer of sputtered Ag was 96-248 nm for GCF-Ag; 70-80 nm, for ACF-Ag (spherulites). According to the photographs of the surface of ACF-Ag fibers (Fig. 4a and 4b), most of the particles were spherical. Spherulites of sizes from 16 to 126 $\mathrm{nm}$ and toroids (sometimes elongated) of sizes from 96 to $248 \mathrm{~nm}$ could be observed among the particles formed on the GCF-Ag surface (Fig. 4c and 4d).

The thickness of the continuous coating of Ag could be characterized by analyzing photographs (Fig. 5), where fragments of the continuous coatings, i.e., the surface layers, separated from the carbon fibers are visible. These layers are $120-130 \mathrm{~nm}$ thick. 
Table 2. Bactericidal Properties of Ag-containing Fibers Used in These Studies

\begin{tabular}{l|cc|c}
\hline \multirow{2}{*}{ Fiber type } & \multicolumn{2}{|c|}{$\begin{array}{c}\text { Diameter of bacteria gro wth } \\
\text { inhibition zone, m m }\end{array}$} & \multirow{2}{*}{ Ref. } \\
\cline { 2 - 3 } & Ps. aeruginosa & St. aureus & \\
\hline ACF & 0 & 0 & This work \\
ACF-Ag & $17.0 \pm 2$ & $17.0 \pm 2$ & \\
\hline GCF & 0 & 0 & Our work \\
GCF-Ag & $13.0 \pm 2$ & $13.0 \pm 2$ &
\end{tabular}

Table 3. Bactericidal Properties of Ag-containing Fibers from the Literature [10,17]

\begin{tabular}{l|cc|c|c|c}
\hline \multirow{2}{*}{ Fiber type } & \multicolumn{4}{|c|}{ Diame ter of bacteria growth inhibition zone, $\mathrm{mm}$} & \multirow{2}{*}{ Ref. } \\
\cline { 2 - 5 } & $\begin{array}{c}\text { S. aureus } \\
\text { VT209 }\end{array}$ & $\begin{array}{c}\text { Ps. } \\
\text { aeruginosa }\end{array}$ & B. subtilis & $\begin{array}{c}\text { St. aureus } \\
\text { ATCC 29213 }\end{array}$ & \\
\hline ACF & 0 & 0 & 0 & - & [17] \\
ACF-Ag & 2.5 & $11.0 \pm 2$ & $11.0 \pm 2$ & - & \\
CF & 0 & 0 & 0 & - & \\
CF-Ag & 3 & $11.0 \pm 2$ & $14.0 \pm 2$ & - & [10] \\
PVDF-Ag & - & - & - & $3.0 \pm 0.2$ & \\
PP-Ag & - & - & - & $2.5 \pm 0.2$ &
\end{tabular}

The Ag-containing fibrous materials possessed antimicrobial activity against Gram-negative and Gram-positive bacteria Pseudomonas aeruginosa and Staphylococcus aureus while the starting fibers did not inhibit the test cultures (Tables 2 and 3). Ag bound to activated fiber substrates suppressed growth of bacteria more than Ag deposited on graphitized fiber. This could indicate that the nature of the fibrous substrate had a specific influence on its bactericidal properties.

The influence of the fiber nature on their bactericidal properties could also be discerned by comparing the properties of GCF-Ag and ACF-Ag fibers with those of previously developed Ag-containing materials PVDF-Ag and PP-Ag (Table 3).

The high bactericidal activity of the Ag-containing carbon-fiber materials could be related to a high positive charge on the filament surface caused by the existence of a double layer formed by the surfaces of the carbon filament and Ag coating (layer). The presence of this double layer determined its redox properties, which helped to maintain a high positive charge on the Ag coating.

With respect to the possible mechanisms of bactericidal activity of Ag-containing materials, i.e., coatings (not nanoparticles as dispersions), we are inclined to suggest that release (diffusion) of $\mathrm{Ag}^{+}$ions into the external medium contributes most to their antibacterial properties because they can actually affect the viability of bacterial cells. Therefore, the previously stated hypothesis about the positive charge of the Ag coatings and particles on the surface of the carbonfiber materials appears completely logical.

Hence, oxidants that are practically always present in aqueous solutions react with $\mathrm{Ag}^{0}$ atoms so that active $\mathrm{Ag}^{+}$ ions migrate into solution. However, the charge of the outer Ag surface layer or particles does not change because carbon (a reductant) in the carbon-Ag double layer is oxidized, which compensates the negative charge of Ag generated after its oxidation. This reaction mechanism with migration of $\mathrm{Ag}^{+}$into the outer medium occurs only because of the conducting metal layer and the existence of pairs of Ag and active carbon-reductant layers. a rougher texture.

Obviously, a layer of activated carbon would be more reactive than a layer of graphitized carbon because it has

A second mechanism of bactericidal and/or bacteriostatic activity could be related to adsorption of bacterial (or viral) cells to the surface coated with reduced Ag. Studies of the adsorption (immobilization) of microorganisms to metallized carbon surfaces have been reported $[16,17]$. The question of what interactions cause adsorption and then retention of cells on the filament surface is still under discussion. In any case, close and direct contact of bacteria and $\mathrm{Ag}$ 
$(\mathrm{Cu}, \mathrm{Zn}$, etc. $)$ on the surface of an adsorbent increases significantly the probability of aggressive action of bactericidal metal ions on cellular structures.

\section{REFERENCES}

1. Yu. A. Bukina and E. A. Sergeeva, Vestn. Kazan. Tekhnol. Univ., 15, No. 14, 170-172 (2012).

2. K. Chaloupka, Y. Malam, and A. M. Seifalian, "Nanosilver as a new generation of nanoproduct in biomedical applications," Trends Biotechnol., 28, No. 11, 580-588 (2010); doi: 10.1016/j.tibtech.2010.07.006.

3. M. Paszkiewicz, A. Golabiewska, et al., "The antibacterial and antifungal textile properties functionalized by bimetallic nanoparticles of Ag/Cu with different structures," J. Nanomater., No. 3, 1-13, Art. ID 6056980 (2016); doi: $10.1155 / 2016 / 6056980$

4. M. V. Antonova, I. V. Krasina, and S. V. Ilyushina, "Methods for achieving antibacterial properties of textile fibers. Review"; https://cyberleninka.ru/article/n/metody-pridaniya-antibakterialnyh-svoystv-tekstilnymvoloknam-obzor/viewer.

5. A. Panacek, L. Kvitek, et al., "Silver colloid nanoparticles: Synthesis, characterization and their antibacterial activity," Phys. Chem. B, 110, No. 33, 16248-16253 (2006); doi: 10.1021/jp063826h.

6. M. S. Antelman, "High performance silver(I,III) oxide antimicrobial textile articles," US Pat. 6,436,420, Aug. 20, 2002.

7. V. A. Zhukovskii, N. I. Mukhina, et al., "Method for making antimicrobial silver-containing mesh endoprosthesis for reconstructive surgery (2 versions)," RU Pat. 2,473,369, IPC A61L 33/02, A61L 27/30, A61L 27/56, D06M 11/01, Jan. 27, 2013.

8. G. E. Krichevskii, Nano-, Biochemical Technologies in Industry of a New Generation of Fibers, Textile and Clothes [in Russian], Moscow, 2011, 528 pp.

9. F. V. Ballyuzek, A. S. Kurkaev, and V.Ya. Skvirskii, Medicinal Silver and Medical Nanotechnologies [in Russian], Dilya, St. Petersburg, 2008, 112 pp.

10. V. A. Zhukovskii, T. Yu. Anyshchenko, et al., Khim. Volokna, No. 4, 12-17 (2018).

11. B. L. Gorberg, A. A. Ivanov, et al., Ross. Khim. Zh., LV, No. 3, 7-13 (2011).

12. E. Matyjas-Zgondek, A. Bacciarelli, et al., "Antibacterial properties of silver finished textiles," Fibres Text. East. Eur., 16, No. 5 (70), 101-107 (2008).

13. C. Lorenz, L. Windler, et al., "Characterization of silver release from commercially available functional (nano) textiles, Chemosphere, 89, No. 7, 817-824 (2012).

14. O. V. Astashkina, L. A. Vol'f, and A. A. Lysenko, Zh. Prikl. Khim., No. 1, 135-139 (1990).

15. O. V. Astashkina, A. A. Lysenko, L. V. Emets, et al., "Polymer-metal composition for sorption of influenza virus," SU Pat. 1,483,915, IPC C08L 29/04, Feb. 20, 2007.

16. O. V. Astashkina, "Preparation of modified chemical fibers - affinity sorbents for virology," Candidate Dissertation in Technical Sciences, S. M. Kirov LITLP, Leningrad.

17. Yu. A. Grineva, Candidate Dissertation in Biological Sciences, http://earthpapers.net/protsess-biotransformatsiitiodiglikolya-uksusnokislymi-bakteriyami-gluconobacter-oxydans.

18. A. A. Lysenko and O. V. Astashkina, Khim. Volokna, No. 2, 44-50 (2007).

19. A. N. Grebenkin, A. A. Shumkov, et al., "Method of metallization flat materials," RU Pat. 2,479,681, IPC C2, Oct. 10, 2012. 